\title{
Pitfalls en RM de próstata multiparamétrica
}

Andrés Labra W. ${ }^{*}$, Álvaro Zúñiga G. $^{1}$

1. Radiólogo Clínica Alemana de Santiago - Universidad del Desarrollo. Santiago, Chile.

\section{Pitfalls in Multiparametric Prostate MRI}

Resumen: La resonancia magnética multiparamétrica (RMmp) de próstata ha tenido un desarrollo importante en los últimos años dado la alta prevalencia del cáncer de próstata y la necesidad de tener información imagenológica concreta para el correcto manejo de los pacientes urológicos. Otras técnicas de imágenes aportan información parcial sobre la morfología de la próstata, pero es la RMmp de próstata la técnica imagenológica que nos entrega mayor información, a través de secuencias morfológicas y funcionales, para detectar lesiones clínicamente significativas y disminuir el número de biopsias, predecir riesgo de agresividad de los tumores, estadificación local y ayudar al urólogo a realizar biopsias dirigidas cognitivas o por fusión RM/US. En este artículo se pretende mostrar casos representativos de errores frecuentes al momento de informar una resonancia magnética de próstata. Damos algunas recomendaciones para evitar estos errores y mejorar los informes radiológicos. Es común al comenzar a realizar informes de RMmp de próstata tener dudas sobre la correcta interpretación de los hallazgos. Ofrecemos a través de este articulo imágenes representativas de los principales errores en la búsqueda de patología neoplásica y algunas sugerencias para evitarlos. Desde el punto de vista académico se pueden dividir en pitfalls de condiciones anatómicas y patologías benignas que pueden simular un tumor. En el caso de pitfalls anatómicos mostramos casos referentes al estroma fibromuscular anterior hipertrófico, cápsula quirúrgica engrosada, plexo venoso peri-prostático, complejo neurovascular y pseudolesión posterior en zona periférica. Dentro de las condiciones benignas se encuentra la hiperplasia prostática benigna, procesos inflamatorios/infecciosos y otras condiciones que pueden simular tumor. Respecto a pitfalls relacionados con la hiperplasia prostática benigna podemos señalar hiperplasia de la zona de transición / central ("moustache-sign"), proliferación estromal en la zona de transición y nódulos adenomatosos ectópicos u extruidos en la zona periférica (ZP). Pitfalls inflamatorios/infecciosos corresponden a casos de prostatitis focal, prostatitis aguda, prostatitis con abscesos y prostatitis granulomatosa. Otros errores frecuentes de dificultad en la interpretación corresponden a casos de calcificaciones y hemorragia.

Palabras clave: Error diagnóstico, Difusión por resonancia magnética, Imágenes diagnósticas, Neoplasia prostática, Próstata, Resonancia Magnética.

Abstract: Multiparameter magnetic resonance imaging (RMmp) of the prostate has had an important development in recent years given the high prevalence of prostate cancer and the need to have specific imaging information for the correct management of urological patients. Other imaging techniques provide partial information about the morphology of the prostate, but it is the $\mathrm{mp}-\mathrm{MRI}$ of the prostate that gives us more information, through morphological and functional sequences, to detect clinically significant lesions and reduce the number of biopsies, predict risk of aggressiveness of the tumors, local staging and help the urologist to perform cognitive biopsies or by MR / US fusion. This article aims to show representative cases of frequent errors when reporting an $\mathrm{MRI}$ of the prostate. We give some recommendations to avoid these errors and improve radiological reports. It is common to start making mp-MRI of the prostate reports having doubts about the correct interpretation of the findings. We offer through this article representative images of the main errors in the search for neoplastic pathology and some suggestions to avoid them. From 
the academic point of view they can be divided into pitfalls of anatomical conditions and benign pathologies that can simulate a tumor. In the case of anatomical pitfalls, we show cases related to the hypertrophic anterior fibromuscular stroma, thickened surgical capsule, peri-prostatic venous plexus, neurovascular complex and posterior pseudo-injury in the peripheral area. Among the benign conditions is benign prostatic hyperplasia, inflammatory / infectious processes and other conditions that can simulate tumor. Regarding pitfalls related to benign prostatic hyperplasia, we can indicate hyperplasia of the transition / central zone ("mustache-sign"), stromal proliferation in the transition zone and ectopic or extruded adenomatous nodules in the peripheral zone. Inflammatory / infectious pitfalls correspond to cases of focal prostatitis, acute prostatitis, prostatitis with abscesses and granulomatous prostatitis. Other frequent errors of difficulty in interpretation correspond to cases of calcifications and hemorrhage.

Keywords: Diagnostic imaging, Diagnostic error, Diffusion Magnetic Resonance Imaging, Magnetic Resonance Imaging, Prostate, Prostate neoplasm.

Labra A, et al. Pitfalls en RM de Próstata MultiparamétricaRev Chil Radiol 2019; 25(4): 128-140.

*Correo electrónico: Andrés Labra Weitzler / alabra@alemana.cl.

Trabajo enviado el 13 de octubre de 2019. Aceptado para publicación el 29 de noviembre de 2019.

\section{Introducción}

La resonancia magnética multiparamétrica $(\mathrm{RMmp})$ de próstata ha tenido un importante desarrollo en los últimos años dado la alta prevalencia del cáncer de próstata. Esta ha demostrado ser una técnica de imágenes superior a cualquier otra técnica de imágenes en evaluar la patología prostática por varias razones, destacando una detallada información anatómica de la glándula prostática. También la RMmp tiene la ventaja de proporcionar información funcional al evaluar los tejidos mediante secuencias de difusión (DWI) y perfusión (DCE). El concepto de multiparamétrica se refiere a que las secuencias de resonancia magnética en forma aislada tienen una precisión limitada en detectar y clasificar a las neoplasias de próstata, pero la asociación de varias secuencias ha demostrado alta exactitud en la evaluación del cáncer de próstata.

La RMmp ha revolucionado el abordaje de los pacientes por parte de la urología permitiendo entender y manejar mejor una patología de alta prevalencia. Muchos urólogos hoy en día no imaginan el atender a sus pacientes sin contar con el apoyo imagenológico de la RMmp, dado que les permite entregar una prestación de mejor calidad al clasificar los pacientes en distintos grupos de riesgo, disminuyendo el número de biopsias sistemáticas innecesarias, dirigiendo biopsias por técnica de fusión en caso de lesiones difíciles y manejando pacientes bajo el concepto de "vigilancia activa".

La palabra del idioma inglés "Pitfall" significa peligro, dificultad, escollo. Es fundamental conocer los pitfalls que se pueden encontrar al informar RMmp de próstata debido a que se pueden interpretar en forma inadecuada y por consiguiente tener un mal manejo en estos pacientes. Con el objetivo de estandarizar los hallazgos encontrados en RMmp de próstata se desarrolló el PI-RADS por parte del American College of Radiology (ACR) y European Society of Urogenital
Radiology (ESUR) similar en sus conceptos al BIRADS desarrollado en la década de los noventa para el abordaje del cáncer de mama. Actualmente está vigente el PI-RADS en su versión 2.1 desde marzo del año 2019 ${ }^{(1)}$. Una adecuada interpretación de la RMmp de próstata necesita conocimiento de la anatómica y patología pélvica, especialmente de la próstata, así como también entender el PI-RADS. EI PI-RADS v2.1 determina "secuencias dominantes" a evaluar en diferentes zonas anatómicas de la próstata, siendo la difusión/mapa ADC las secuencias dominantes en la zona periférica y las secuencias de alta resolución potenciadas en T2 las dominantes en la zona central. En esta revisión se pretende dar énfasis a casos de pitfalls y se entregan sugerencias para evitarlos en el trabajo clínico diario. Los pitfalls se pueden dividir en condiciones anatómicas de la glándula prostática, entre ellas del estroma fibromuscular anterior (FMA), cápsula quirúrgica, pseudolesión posterior de la ZP (tear drop sign), plexos venosos periprostáticos y complejo neurovascular, que pueden simular una cáncer y condiciones benignas derivadas de la hiperplasia prostática benigna, patología inflamatoria/infecciosa y otras condiciones que pueden simular patología neoplásica maligna (Tabla 1) $2,3,4,5,6)$.

\section{Condiciones Anatómicas}

\section{a. Estroma fibromuscular anterior hipertrófico} (pitfall anatómico)

El estroma fibromuscular anterior corresponde a una banda de tejido formado por células musculares y tejido conectivo sin presencia de tejido glandular que se ubica anterior a la zona de transición de la glándula prostática. En base a su composición histológica (células musculares y tejido conectivo) se desprende la baja intensidad de señal en secuencia T2, lo que puede llevar a confusión dado que los cánceres de próstata también presentan baja señal 
Tabla 1. Clasificación académica de los Pitfalls en RMmp de próstata.

\begin{tabular}{|l|}
\hline \multicolumn{1}{|c|}{ PITFALL } \\
\hline 1. ANATÓMICOS \\
a) Estroma fibromuscular hipertrófico \\
b) Cápsula quirúrgica \\
c) Plexo venoso peri-prostático \\
d) Complejo neuro-vascular \\
e) Pseudolesión posterior (tear drop sign) \\
CONDICIONES PATOLÓGICAS BENIGNAS \\
a) Hiperplasia Prostática Benigna \\
- Moustache sign \\
- Hiperplasia estromal en zona de transición \\
- Nódulo adenomatoso extruido \\
b) Patología inflamatoria / infecciosa \\
- Prostatitis focal \\
- Prostatitis aguda \\
- Prostatitis con abscesos \\
- Prostatitis granulomatosa \\
c) Otros \\
- Hemorragias \\
- Calcificaciones
\end{tabular}

en secuencias potenciadas en T2. Si hay dudas al evaluar el estroma fibromuscular anterior en secuencia T2, debemos evaluar la secuencia funcional de difusión/mapa ADC y las adquisiciones en perfusión. Normalmente el estroma fibromuscular anterior no presenta restricción a la difusión, así como tampoco representación precoz en las secuencias de perfusión (Figura 1).

\section{b. Cápsula quirúrgica (pitfall anatómico)}

La cápsula quirúrgica corresponde a un tejido fibroso concéntrico que normalmente se encuentra separando la zona de transición y la zona periférica de la próstata. Al igual que el estroma fibromuscular anterior es un tejido de soporte conectivo de la próstata y por su histología presenta baja señal T2 en forma normal. Es una estructura lineal, sin conformar un aspecto pseudonodular, nodular ni masa. En el aspecto lateral pudiese simular patología neoplásica al mostrar alguna asimetría en el mapa ADC cuando hay algún grado de engrosamiento de la cápsula quirúrgica, pero la correlación con secuencias T2 de alta resolución y de perfusión nos ayudan a diferenciarla de patología maligna (Figura 2).

\section{c. Plexo venoso peri prostático (pitfall anatómico)}

La proximidad del plexo venoso peri-prostático a la glándula prostática es un desafío en evaluar lesiones de la zona periférica. También llamado plexo de Santorini, está íntimamente en contacto con la cápsula prostática, variando la dilatación de los vasos venosos entre pacientes, encontrándose más dilatados los plexos venosos en pacientes con procesos inflamatorios, muchas veces en forma asimétrica. Puede tener una forma redondeada en las imágenes axiales, alta o baja señal T2 (dependiendo de la velocidad del flujo de la sangre dentro del vaso y consiguiente vacío de señal que determina) y baja señal en mapa ADC. Estos hallazgos normales pueden llevar a confusión con una lesión sospechosa. Para evitar este pitfall, debemos conocer la ubicación del
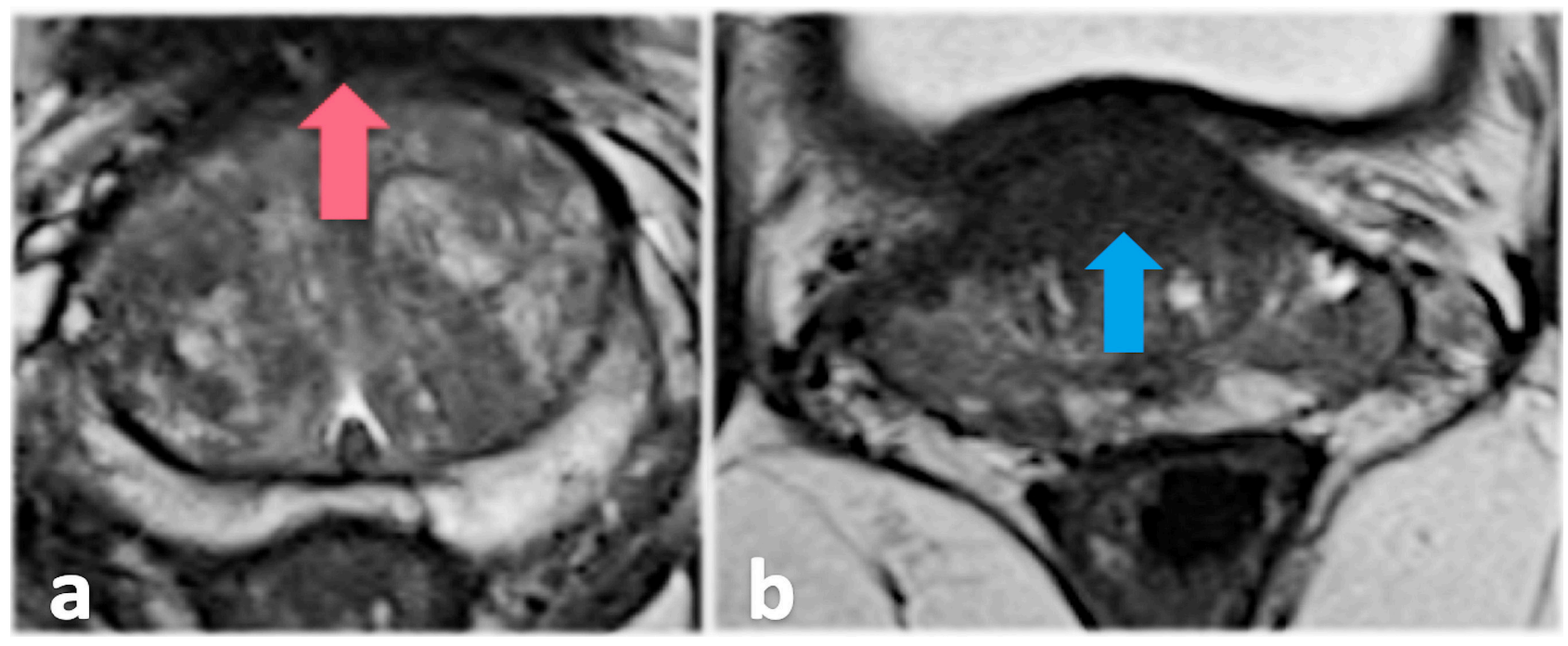

Figura 1: Estroma fibromuscular anterior normal. Pitfall anatómico. La flecha roja (a) muestra el estroma fibromuscular anterior de grosor normal. La flecha azul (b) muestra hipertrofia del estroma fibromuscular en un segundo paciente. Ambas imágenes T2 axiales. Ninguno de estos pacientes presentaba restricción en secuencia de DWI/mapa ADC ni impregnación con el contraste. 


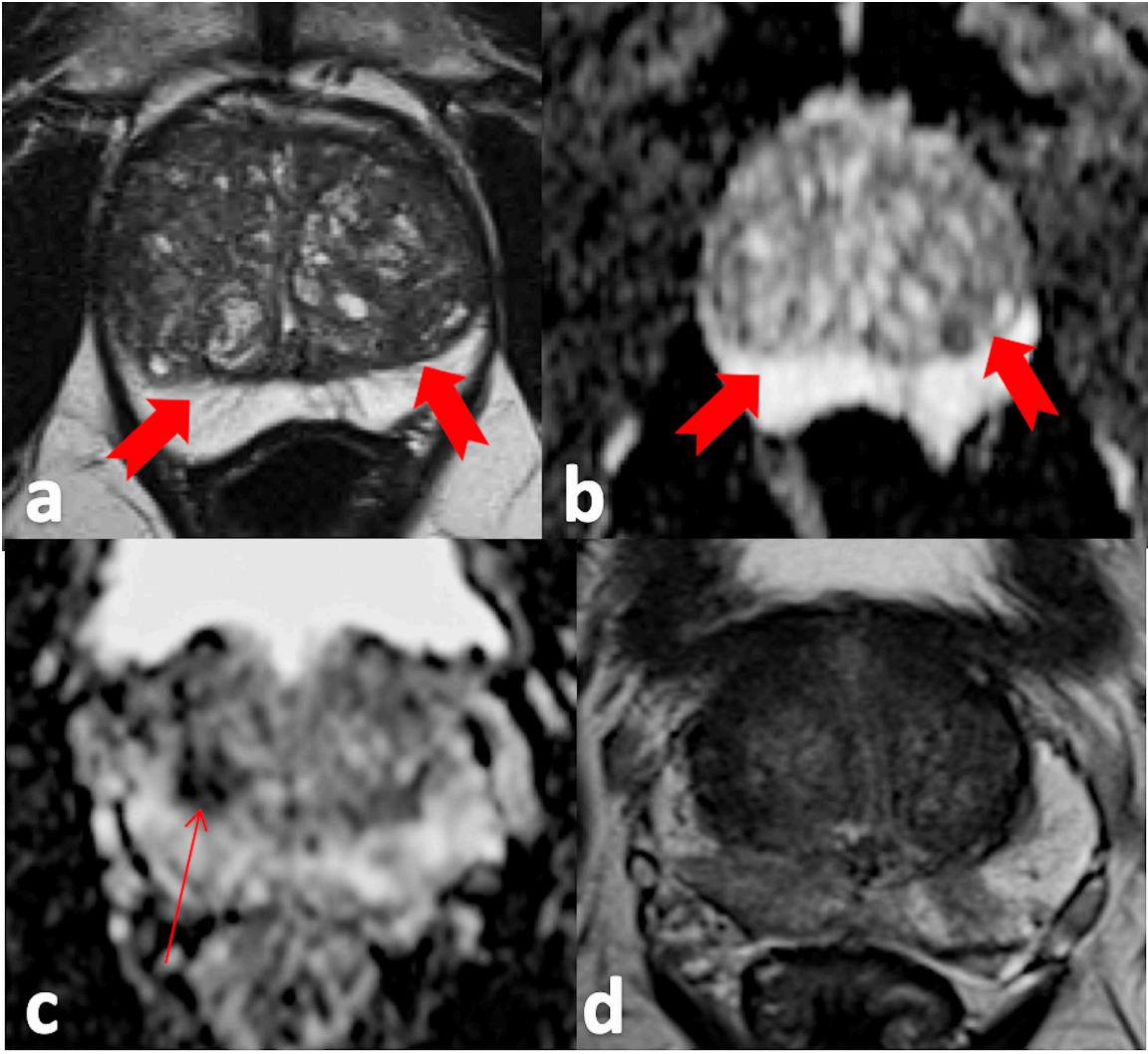

Figura 2: Cápsula quirúrgica. Pitfall anatómico. Con las flechas gruesas en (a) y (b) podemos identificar la cápsula quirúrgica normal en secuencia T2 y mapa $A D C$ respectivamente. En (c) se identifica pseudotumor (flecha delgada) en el aspecto lateral de la cápsula quirúrgica, el cual no tiene representación en secuencia T2. plexo venoso periprostático, el cual se encuentra en el aspecto antero-lateral de la zona periférica. Se debe considerar que, si se evalúa una lesión sospechosa de baja señal en mapa ADC, ésta se debe evaluar detalladamente en secuencia morfológica potenciada en T2, ya que ésta última tendrá mejor resolución espacial (Figura 3).

\section{d. Complejo neurovascular (pitfall anatómico)}

El complejo neuro-vascular que inerva a los cuerpos cavernosos está en contigüidad a la próstata. La preservación de este plexo es determinante en la función sexual post prostatectomía, sin embargo, en caso que una lesión neoplásica comprometa al complejo neuro-vascular el urólogo se verá obligado a practicar una resección más amplia. Los complejos neuro-vasculares son normalmente visualizados como estructuras que recorren el margen póstero-lateral de la próstata, cerca de la cápsula, habitualmente a la hora 5 y hora 7 del reloj. El complejo neuro-vascular puede tener una apariencia redondeada en las imágenes axiales, de baja señal T2 y baja señal en el mapa ADC. Dada la distorsión de la imagen en el mapa ADC la imagen del complejo neuro-vascular pudiese parecer estar en la zona periférica y simular un nódulo. Clave es mirar las secuencias T2 de alta resolución (Figura 4).

\section{e. Pseudolesión posterior (Teardrop sign)}

Esta condición benigna que puede simular patología neoplásica corresponde a la fusión y engrosamiento de la cápsula prostática-fascia en la línea media, en la unión de ambos lóbulos, rodeando los conductos eyaculadores. Se pudiese considerar como una variante del "moustache sign". También llamado teardrop sign por su forma que asemeja a una lagrima. Esta pseudolesión se encuentra en la línea media a nivel de la base-tercio medio de la glándula, adyacente a los conductos eyaculadores (Figura 5). La clave aquí es primero conocer esta pseudolesión y mirar las secuencias T2 en los tres planos.

\section{Condiciones patológicas benignas}

\section{a. Hiperplasia prostática benigna}

- Hiperplasia bilateral con compresión de ZP (Moustache Sign)

Corresponde a un patrón que se asemeja a un bigote, de ahí su nombre. Es el resultado de pequeños nódulos adenomatosos de la zona de transición en forma simétrica, que determina compresión de la zona periférica y central en la base de la glándula prostática. La simetría o asimetría es clave para determinar si se está en frente de un verdadero "moustache sign" o una lesión sospechosa clínicamente significativa 

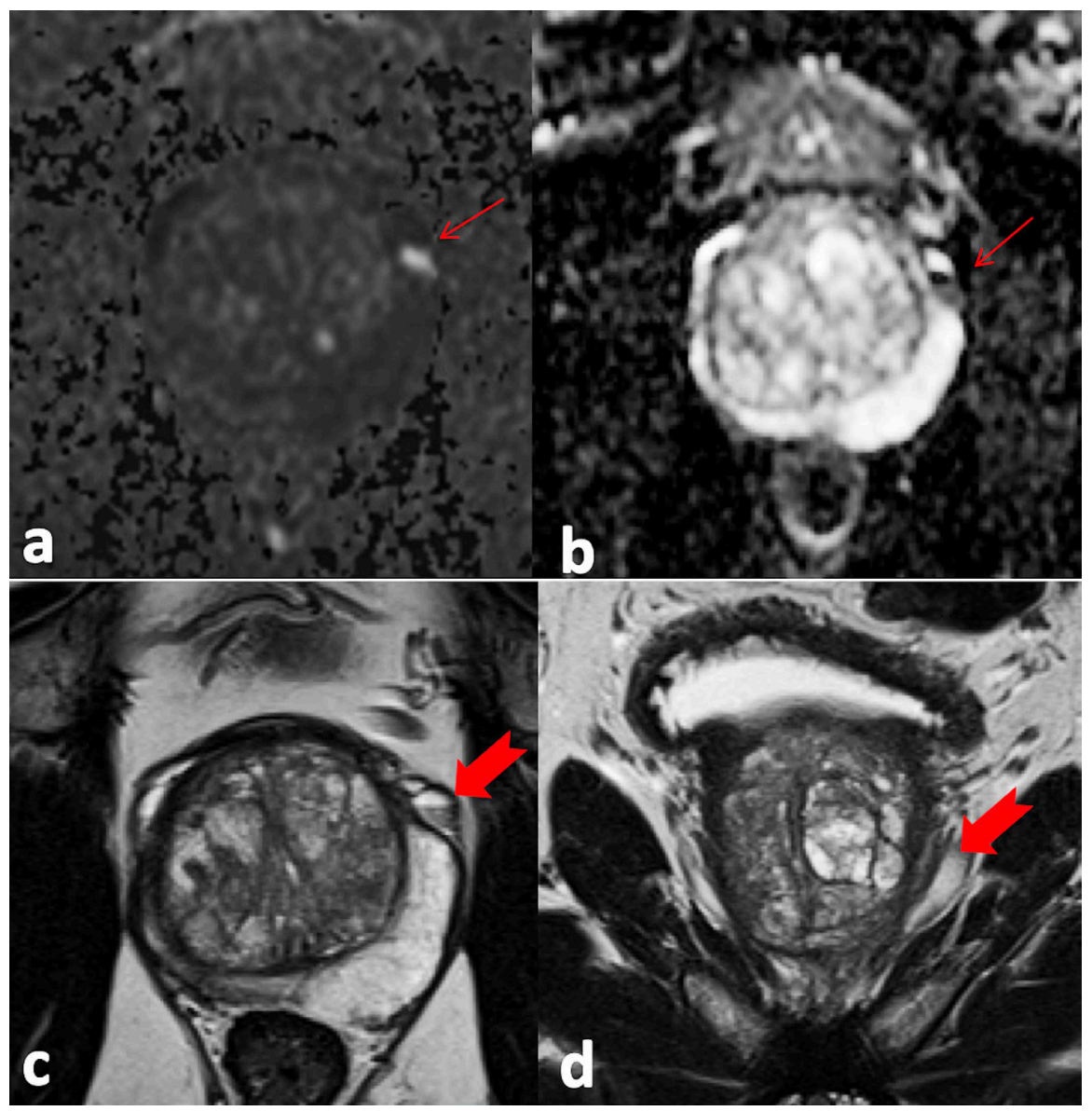

Figura 3: Plexo venoso peri prostático. Pitfall anatómico. La flecha roja muestra en DWI (a) y en mapa ADC (b) una potencial lesión sospechosa. La flecha roja en las secuencias T2WI de alta resolución en axial (c) y coronal (d) muestra que corresponde a una pseudolesión, y que corresponde al plexo venoso periprostático.

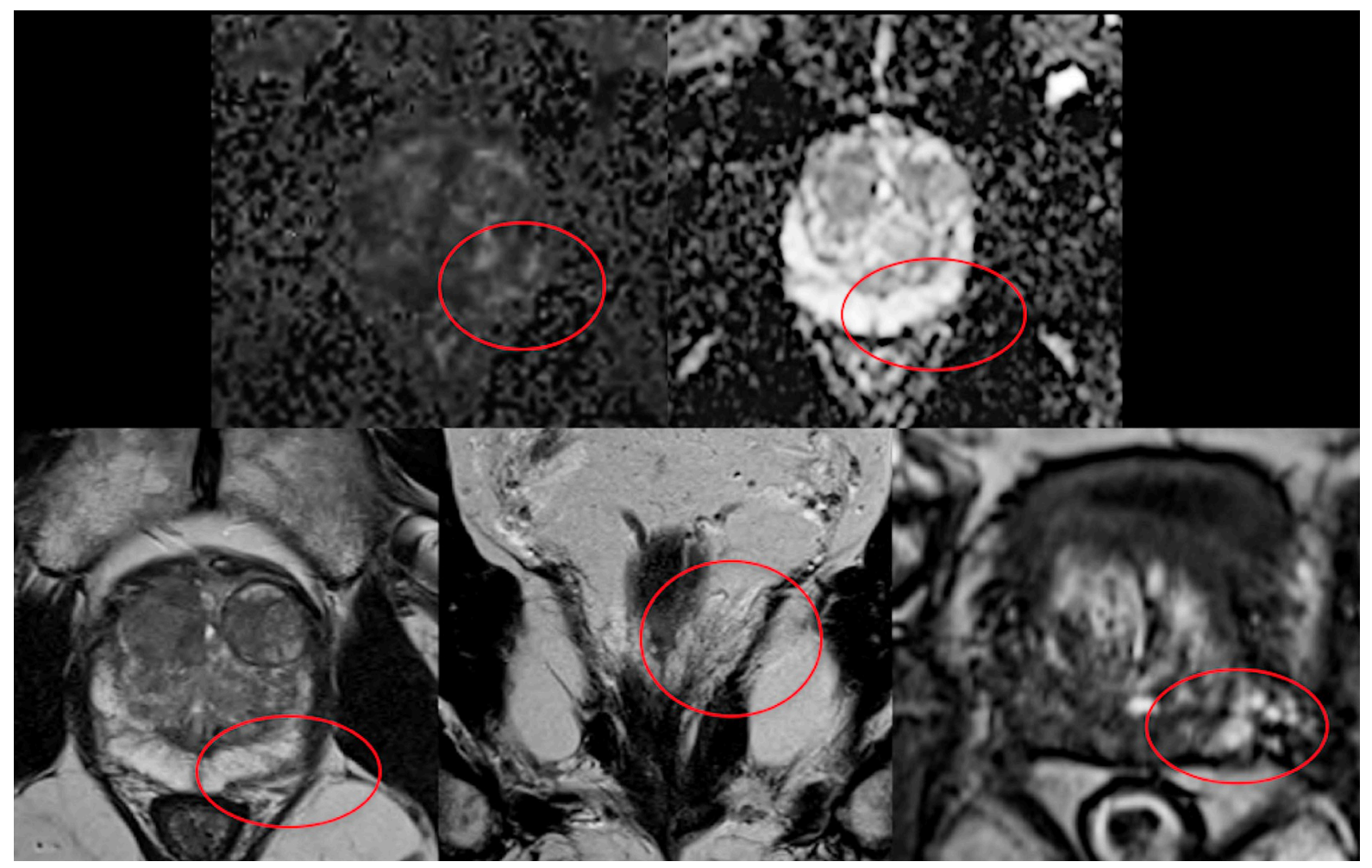

Figura 4: Complejo neurovascular. Pitfall anatómico. A la hora 7, en la periferia de la próstata se puede identificar una estructura de baja señal T2, de baja señal en mapa ADC y realce con el contraste intravenoso correspondiente al complejo neurovascular del lado izquierdo. 


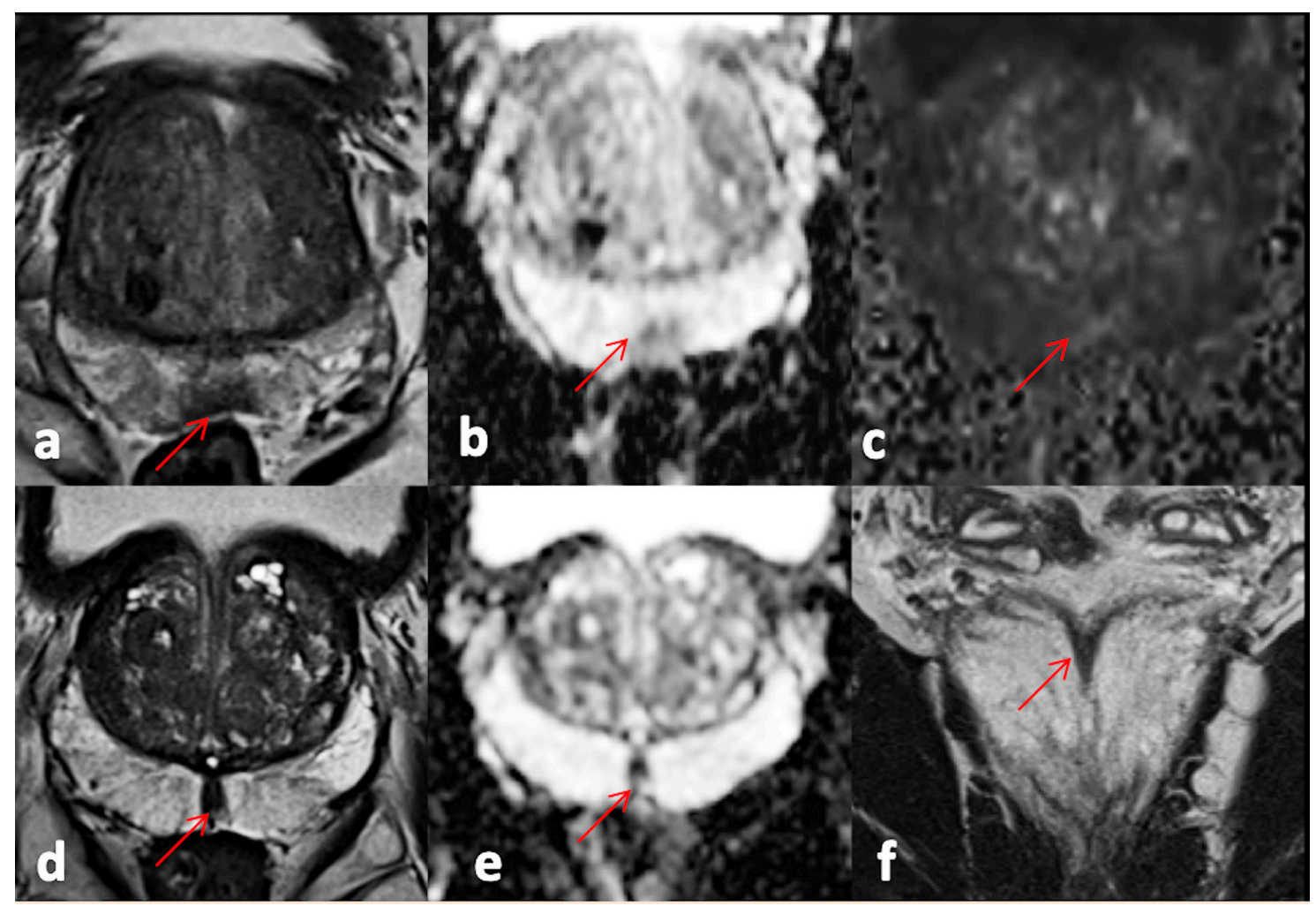

Figura 5: Pseudolesión posterior (Teardrop sign). Pitfall relacionado con hiperplasia prostática. Dos diferentes pacientes con pseudolesión posterior. En a, b y c imágenes de un primer paciente y en d, e y f un segundo caso. En ambos podemos identifican en la línea media el signo de la lagrima (Teardrop sign) que corresponde a fibrosis o bien engrosamiento capsular en la unión de ambos lóbulos prostáticos. En T2 coronal (f) queda demostrado la ubicación en la línea media de la base de la próstata.

en esta misma área, especialmente al evaluar en secuencia T2 coronal (Figura 6).

- Proliferación de hiperplasia prostática subtipo estromal en zona de transición

La hiperplasia prostática benigna posee las variantes glandular y estromal, siendo esta última con de baja intensidad de señal T2, lo que puede hacer confundir con tumor. Debido a que la hiperplasia prostática benigna en la zona de transición es más heterogénea y multinodular la identificación de lesiones clínicamente significativas es más difícil. Las secuencias T2 de alta resolución son las de mayor utilidad para identificar un nódulo hiperplásico, generalmente redondo u ovalado, rodeado de una cápsula bien definida. Las lesiones clínicamente significativas tienden a tener forma lenticular, "en lagrima" o irregulares, o francamente se extienden hacia el estroma fibromuscular anterior o la zona periférica. En varias ocasiones no es fácil hacer la diferenciación, y eventualmente nos podemos apoyar en la secuencia de difusión/mapa ADC, buscando en nuestro valor-b más alto, para aumentar la confianza en nuestra evaluación de la posible lesión neoplásica clínicamente significativa (Figura 7).

\section{- Nódulo adenomatoso ectópico u extruido} Los nódulos adenomatosos ectópicos son un pitfall recurrente en radiólogos con menos experiencia al interpretar RMmp de próstata. Pueden simular cáncer dada su naturaleza redondeada, baja señal T2, en algunos casos pueden presentar restricción a la difusión y baja señal en mapa ADC con realce en estudio de perfusión (DCE). La clave está en definir la capsula de baja señal T2 que lo rodea (Figura 8). Éstos se pueden encontrar en la zona periférica u protruir desde la zona de transición hacia la zona periférica (extruidos).

\section{b. Patología Inflamatoria / infecciosa \\ - Prostatitis focal}

Las prostatitis son siempre un desafío diagnóstico en RMmp y más en caso de presentarse en forma focal, debido a que tendremos una lesión delimitada y aumento del antígeno prostático específico (APE) por lo que rápidamente se puede interpretar como una lesión sospechosa 


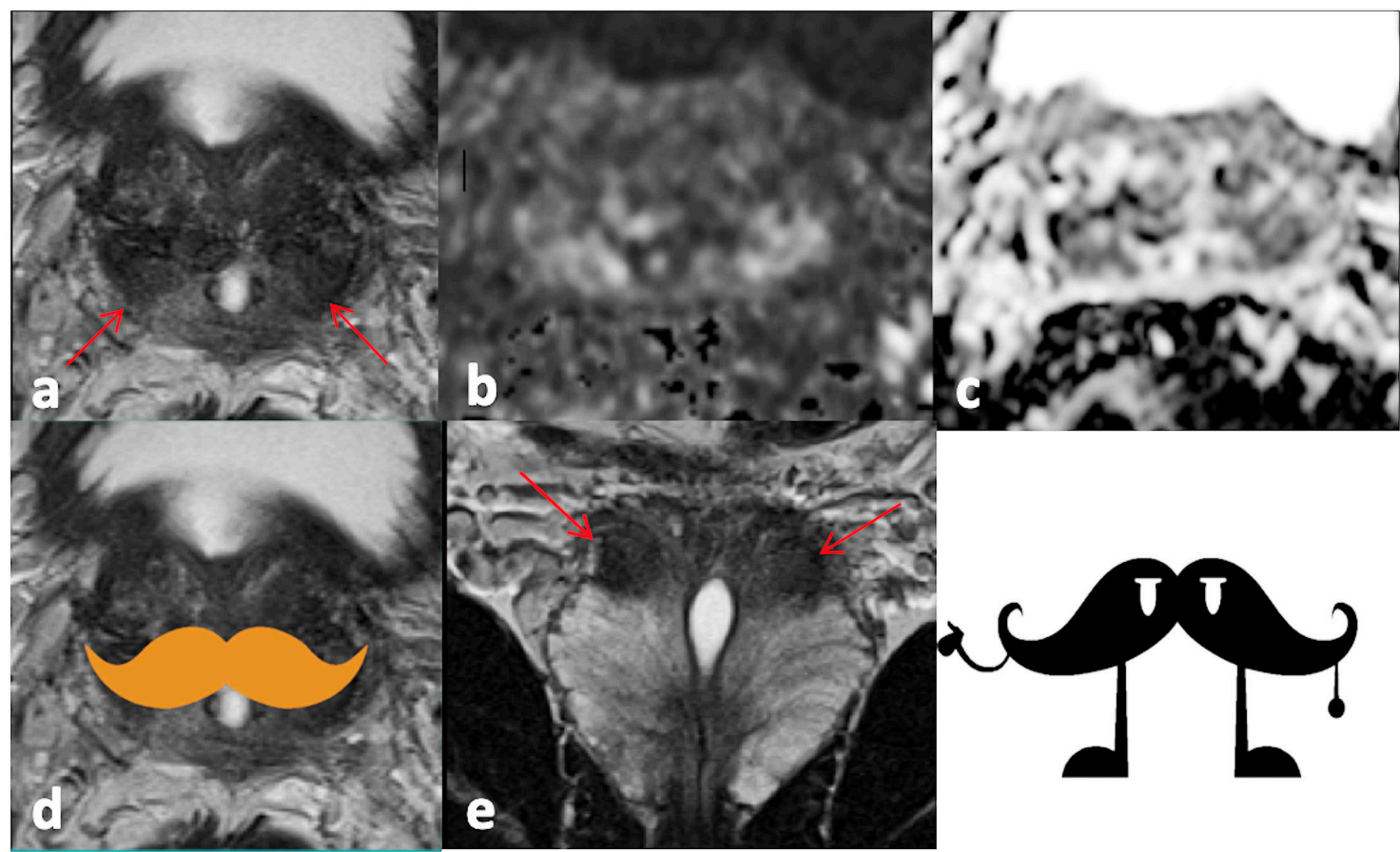

Figura 6: Moustache Sign. Pitfall relacionado con hiperplasia prostática. Las flechas rojas señalan la baja señal T2 (a) que determinan un patrón de morfología en bigote ("Moustache Sign"). En DWI-ADC (b y c), se identifica restricción, pero que corresponde a zona central comprimida. En T2 coronal (e) se confirma que los hallazgos corresponden a una condición benigna, dado la simetría de los hallazgos.

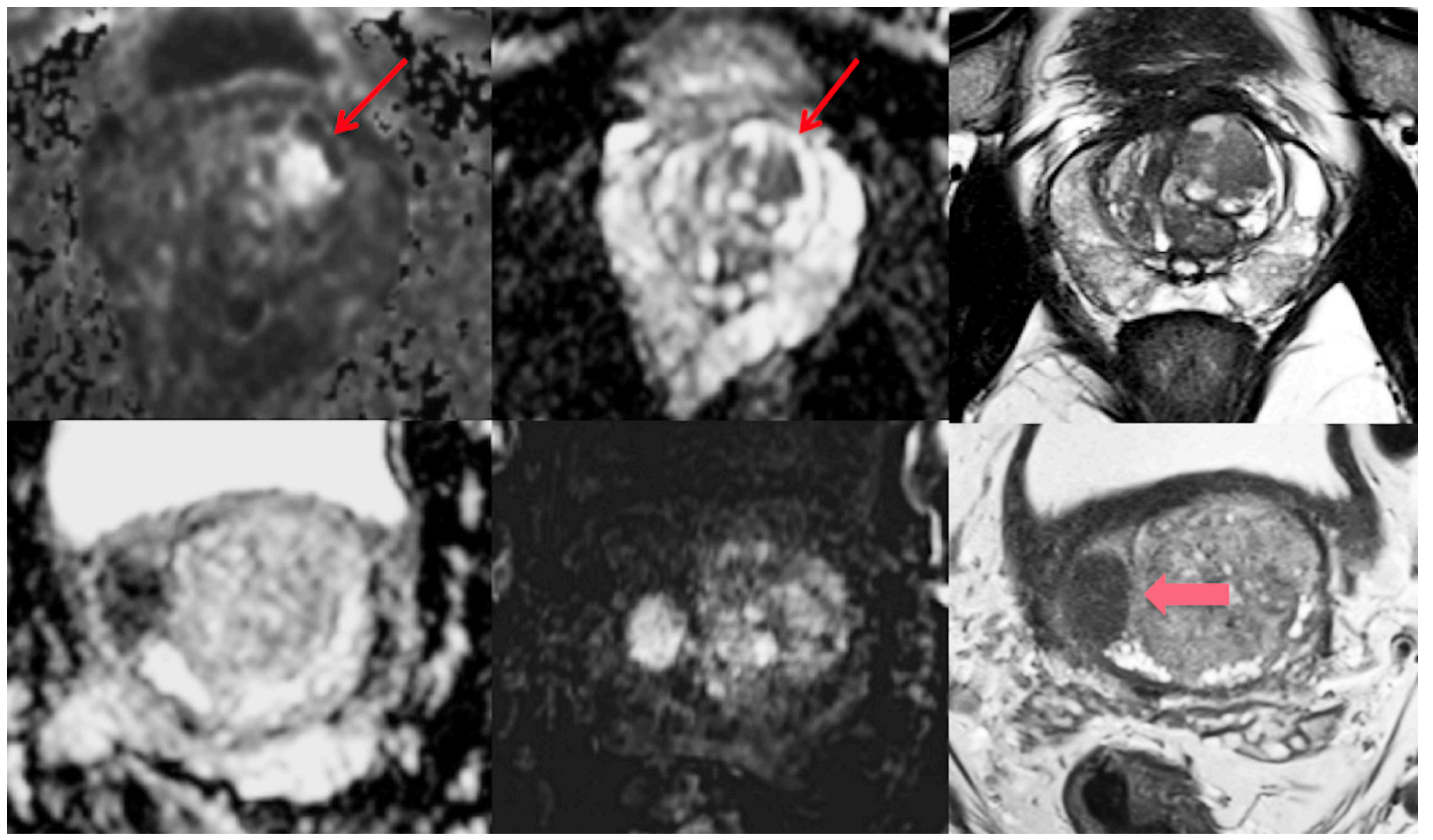

Figura 7: Hiperplasia estromal en zona de transición. Pitfall relacionado con hiperplasia prostática. En la zona de transición identificamos nódulo hiperplásico en dos pacientes diferentes (flechas rojas). La clave es identificar que es una lesión de forma redondeada, de márgenes definidos y rodeado por cápsula. 


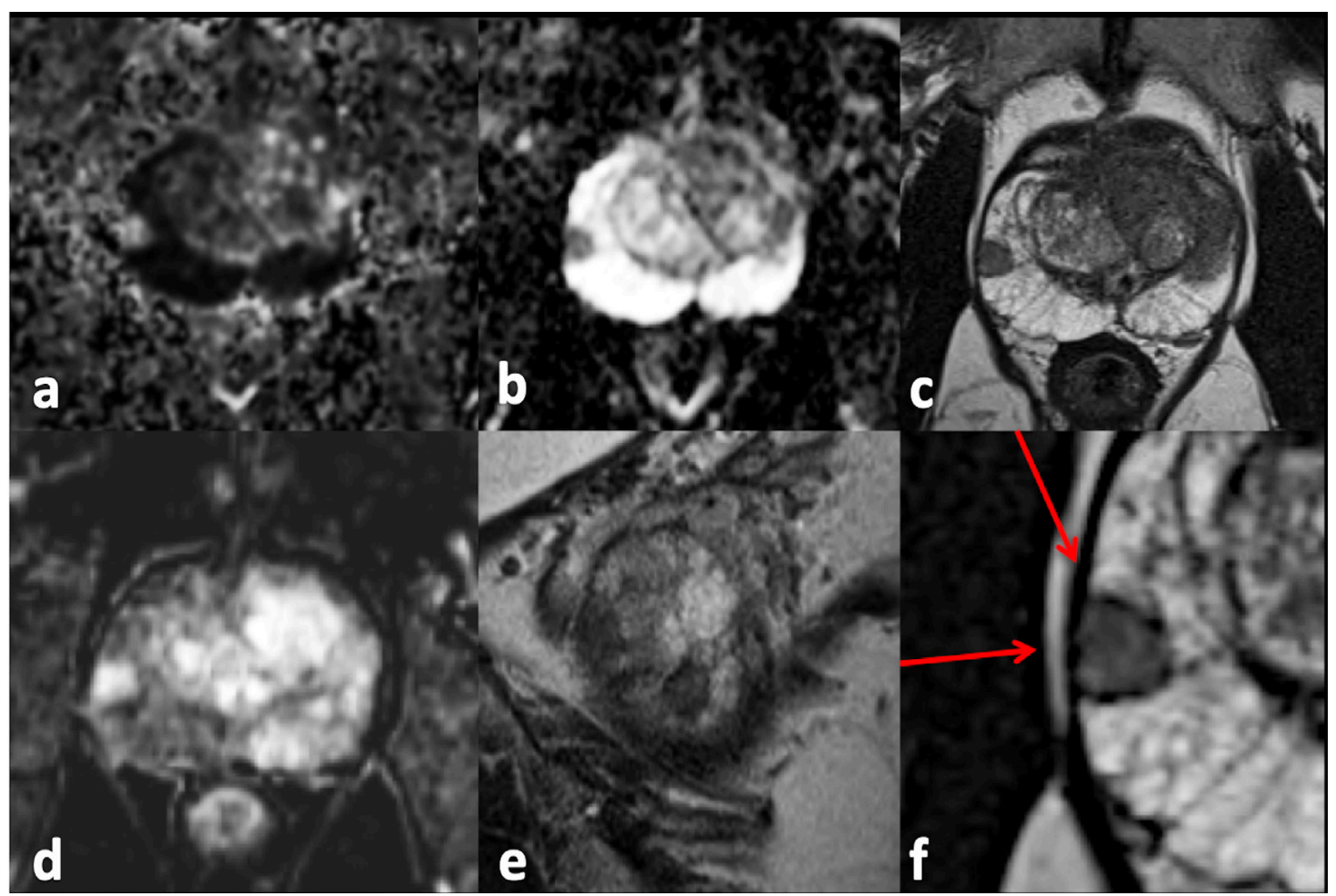

Figura 8: Nódulo adenomatoso ectópico. Pitfall relacionado con hiperplasia prostática. Nódulo adenomatoso ectópico en la zona periférica a derecha que muestra restricción en DWI (a), baja señal en ADC (b), baja señal T2 (c), e impregnación con el contraste endovenoso (d). En (f) podemos claramente ver la cápsula que lo rodea y determinar que corresponde a un nódulo adenomatoso ectópico.

por un radiólogo con poca experiencia. Existen ocasiones en que no es del todo distinguible, por lo que el seguimiento nos dará el resultado final. En general estas lesiones tienen una configuración en cuña mal definida o bien estriada focal en secuencia T2 en la ZP siendo el hallazgo más relevante para diferenciarlo de una lesión sospechosa, con cierto grado de restricción en DWI y baja señal en mapa ADC e impregnación en estudio de DCE. El mapa ADC nos puede ayudar a tener una aproximación dado que los cánceres pueden tener un valor de ADC más bajo que la prostatitis focal (Figura 9). Se debe estar atento a los antecedentes debido a que si existe historia clínica de prostatitis inclinará la balanza hacia hallazgos benignos, en cambio si la lesión que estamos evaluando corresponde a un hallazgo incidental en un paciente asintomático, quizás estamos frente a una lesión sospechosa clínicamente significativa.

\section{- Prostatitis aguda}

La prostatitis aguda es un diagnóstico clínico basado en los síntomas y signos del paciente, donde encontraremos un paciente enfermo en forma aguda, con un ambiente inflamatorio que se pudiese expresar por compromiso del estado general, fiebre, disuria y/o incontinencia. El urólogo sospecha el diagnóstico y el tacto rectal es característico (próstata sensible). Generalmente corresponden a infecciones bacterianas Gram negativas, las cuales presentan una vía de colonización ascendente a través de la vía urinaria. También se pueden producir por inoculación directa a través de procedimientos tal como biopsias o cistoscopias. Las imágenes tienen como objetivo el evaluar la presencia de eventuales complicaciones tales como abscesos o diseminación por contigüidad a estructuras adyacentes (articulaciones sacro-iliacas, por ejemplo). Podemos encontrar casos con cambios inflamatorios difusos (Figuras 10 y 11), así como también casos complicados con abscesos prostáticos (Figura 12).

\section{- Prostatitis granulomatosa}

Se debe conocer y tener en mente la prostatitis granulomatosa. Corresponde a una inflamación crónica, que en la mayoría de los casos es idiopática (60\%). Puede tener etiologías identificables tal como exposición a tratamiento intra-vesical con BCG en contexto de cáncer vesical. Es importante contar con los ante- 


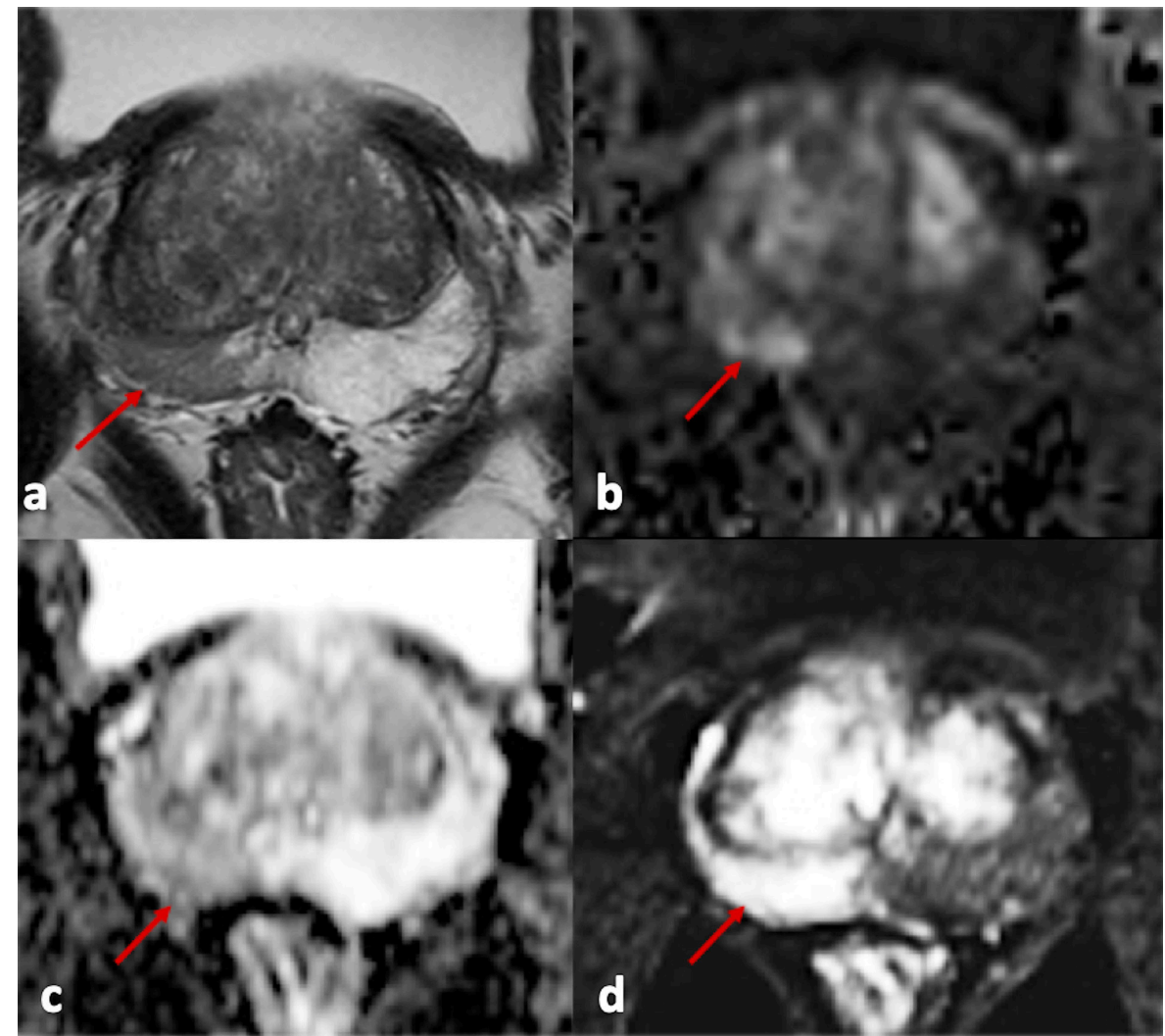

Figura 9: Prostatitis focal. Pitfall inflamatorio / infeccioso.Se identifica en T2 axial, en la zona periférica a derecha, alteración difusa de la señal (a). Esta misma zona presenta restricción en DWI (b), pero su mapa ADC no presenta tan baja señal (c). Existe captación aumentada del contraste endovenoso en la misma área en secuencia DCE (d). En este caso el paciente presentaba aumento del PSA (15 ng/ml) y tenía 2 biopsias trans-rectales negativas para neoplasia.

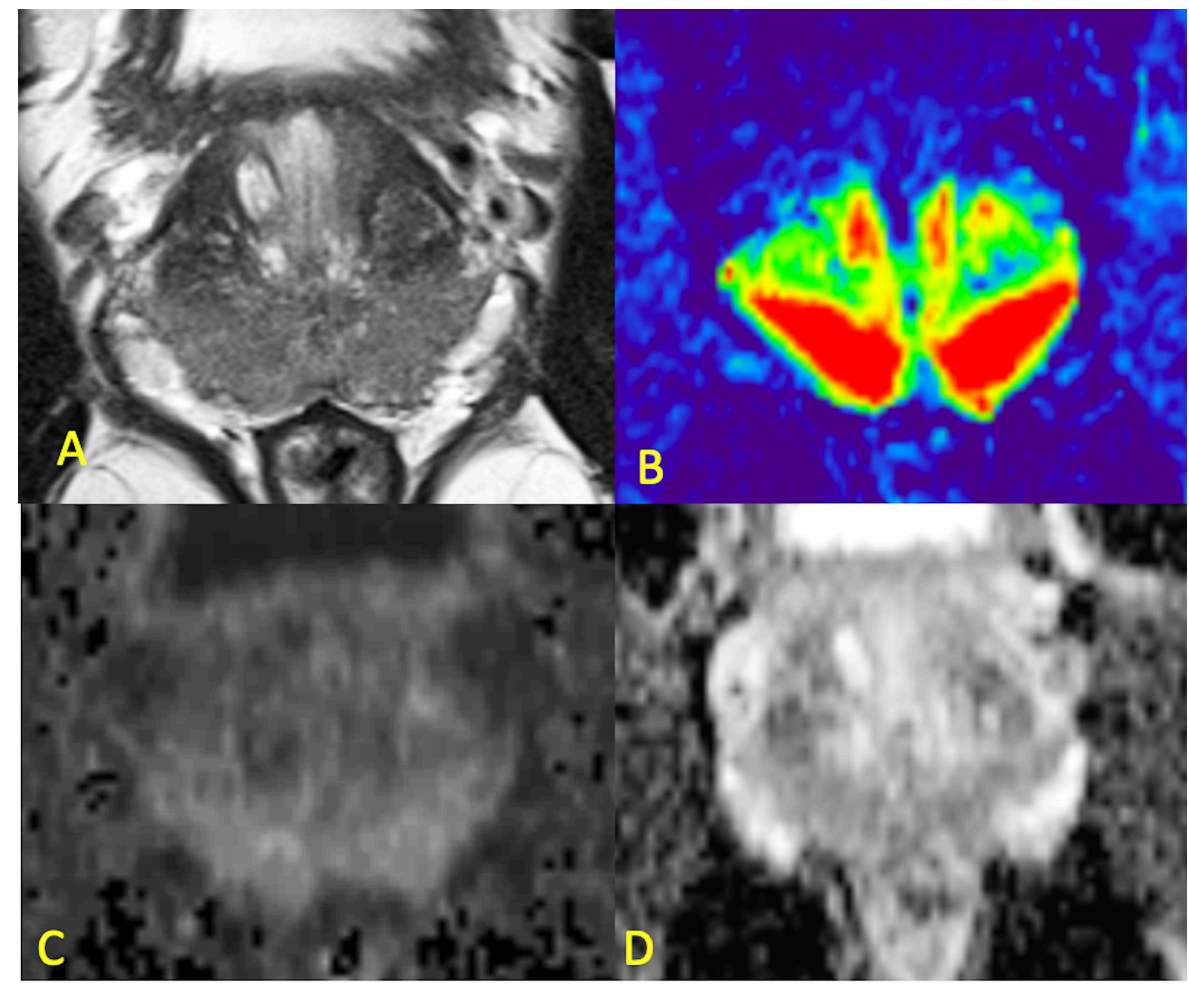

Figura 10: Prostatitis aguda sin abscesos. Pitfall inflamatorio / infeccioso. Paciente de 45 años con aumento de antígeno prostático específico $(12,05 \mathrm{ng} / \mathrm{ml})$. En las imágenes se observa alteración difusa de la señal en T2 (A), con marcado aumento de la perfusión con el contraste endovenoso (B). En secuencia de difusión (C) existe restricción con discreta hipointensidad de señal en mapa $A D C(D)$. 


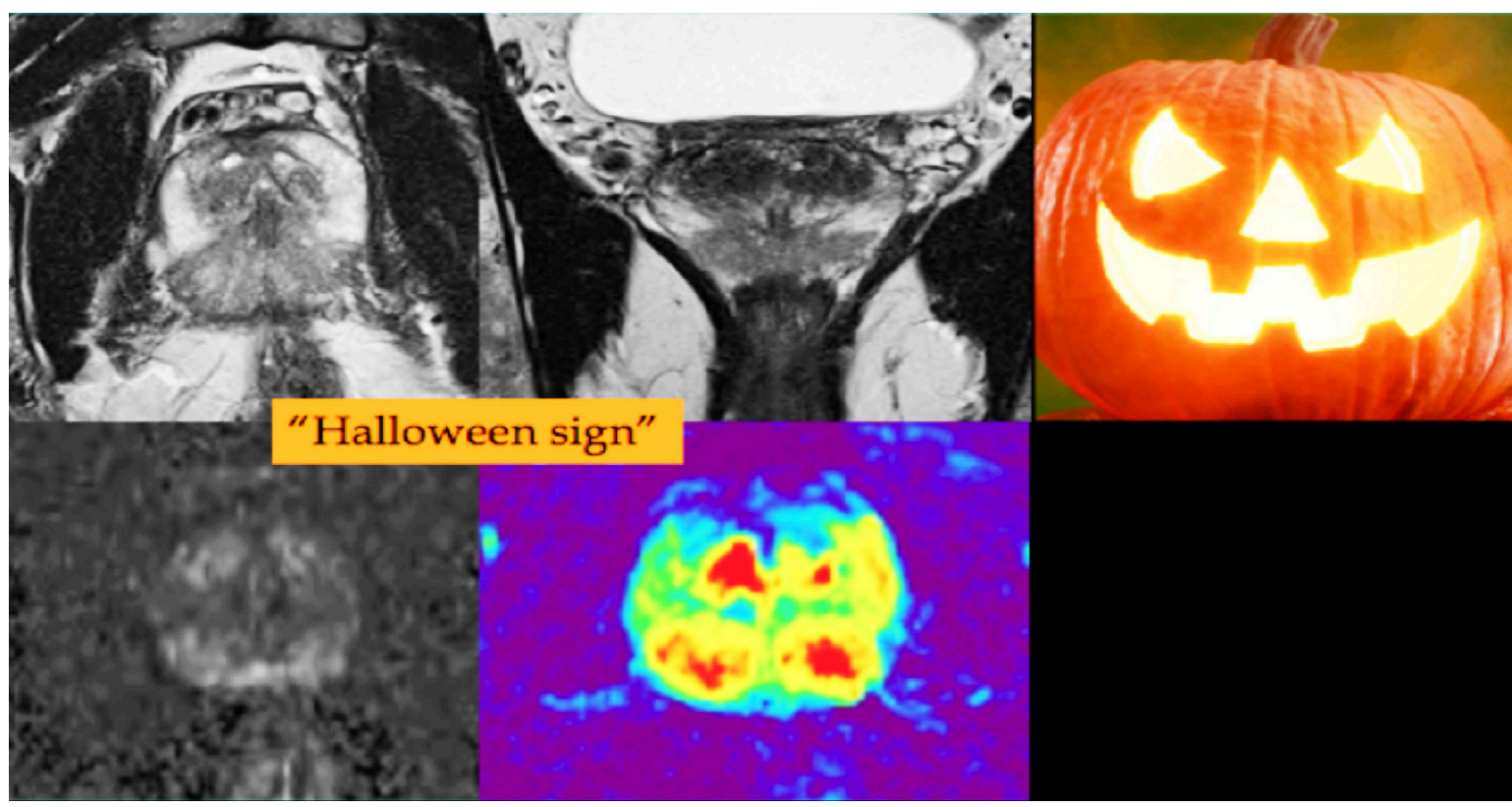

Figura 11: Prostatitis aguda sin abscesos. Pitfall inflamatorio / infeccioso. Paciente de 56 años con elevación del antígeno prostático específico (17 ng/ml). El aumento difuso de la perfusión en la glándula determina el signo de "Halloween", por su similitud con una calabaza.

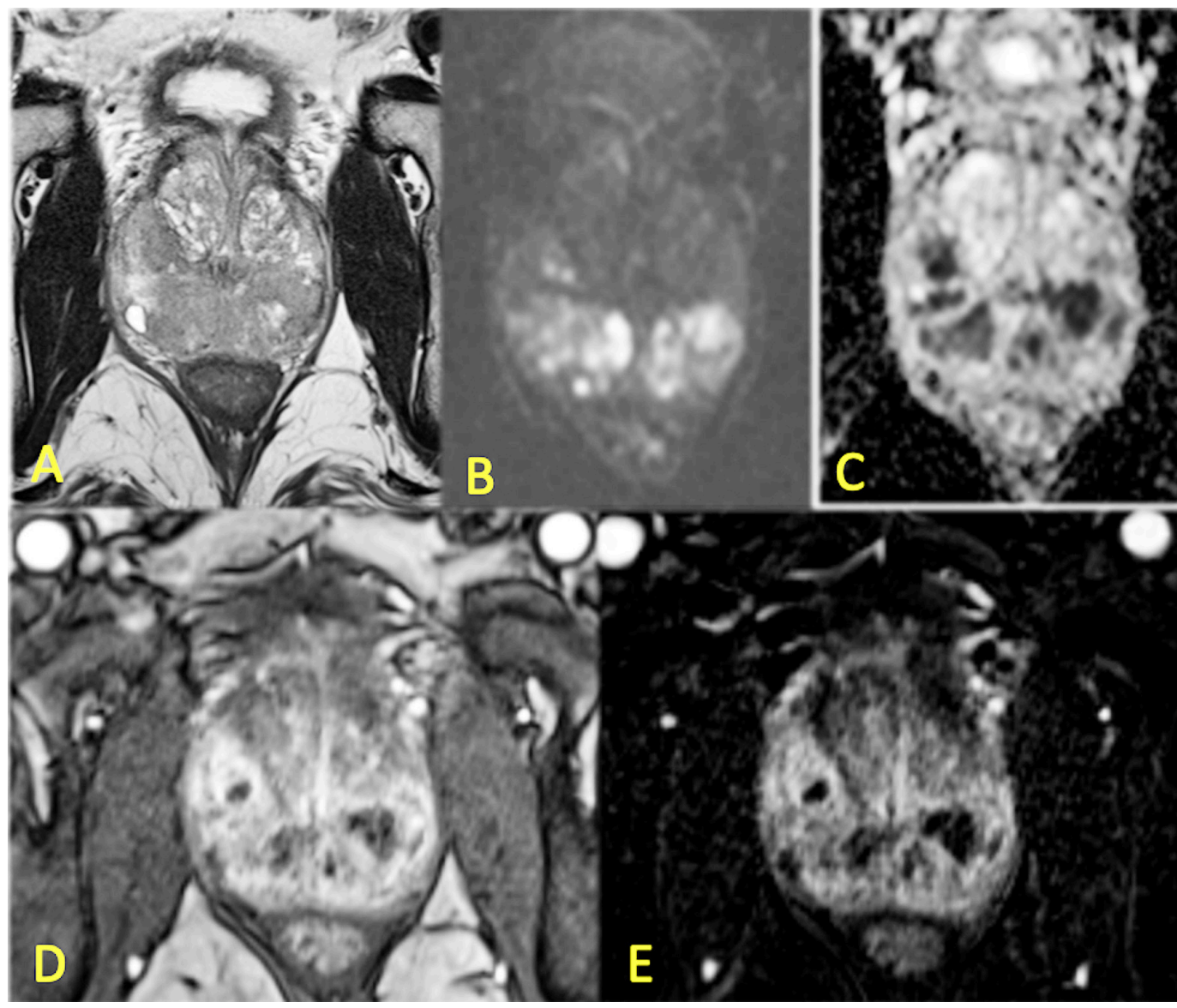

Figura 12: Prostatitis aguda difusa con abscesos. Pitfall inflamatorio / infeccioso. Paciente febril con parámetros inflamatorios elevados. Aumento del PSA $(15,76 \mathrm{ng} / \mathrm{ml})$. La prostatitis aguda con abscesos se puede mal interpretar como una lesión sospechosa en secuencia T2 (A), DWI (B) y ADC (C), dado que su comportamiento de señal es bastante similar. La clave está en evaluar la secuencia de perfusión (DCE) (D) y su respectiva sustracción (E), que muestran que las múltiples lesiones nodulares no corresponden a lesiones sospechosas de neoplasia sino a abscesos, que presentan solo impregnación periférica. 
cedentes clínicos al momento de realizar la interpretación del estudio. En la gran mayoría de los casos las imágenes tanto en secuencias morfológicas (T2) y funcionales de DWI y DCE son indistinguibles de una lesión neoplásica clínicamente significativa, incluso con signos de extensión extra-prostática y diseminación ganglionar pelviana (Figura 13).

\section{c. Otros (hemorragia, calcificaciones) \\ - Hemorragia post-biopsia}

La sangre presenta característicamente en algunos de sus estados metabólicos alta señal en secuencia T1 y baja señal en secuencia T2, por lo que podría confundir en caso de que exista hemorragia previa a la RMmp, generalmente post-biopsias. Este pitfall, es cada vez menos frecuente dado que habitualmente la RMmp se está realizando antes de las biopsias y en caso de realizarse en forma posterior se ha aprendido esperar al menos 6-8 semanas entre la biopsia y la RMmp. La sangre de la hemorragia podría tener baja señal en T2 y morfología focal, y hacer pensar en forma equivocada un foco de neoplasia (Figura 14).

\section{- Calcificaciones}

Las calcificaciones prostáticas son frecuentes y se deben básicamente a secreciones. Se encuentran generalmente en la zona de transición o entre la zona de transición y la zona periférica. La mayoría de las veces son indolentes. Por su naturaleza cálcica presentan baja señal T2 y baja señal en el mapa ADC, sin embargo, no presentan restricción en DWI y evidencian baja señal en T1 (Figura 15).

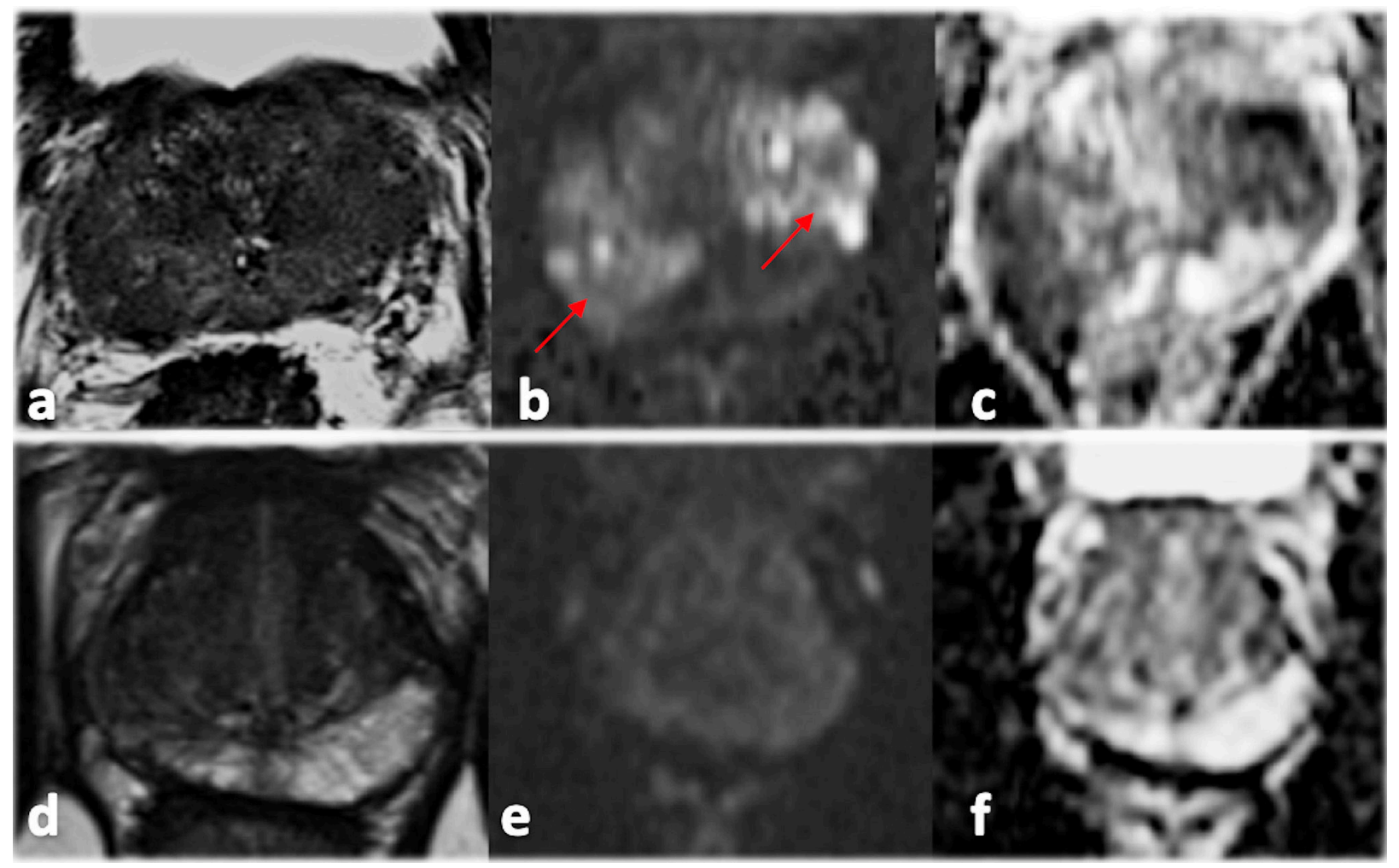

Figura 13: Prostatitis granulomatosa. Pitfall inflamatorio / infeccioso RMmp inicial / PSA $27 \mathrm{ng} / \mathrm{ml}$, en tratamiento con BCG intra-vesical por antecedente de neoplasia urotelial pT1. En RMmp inicial existen áreas difusas de baja señal T2 (a), las cuales presentan restricción a la difusión (flechas rojas en b) con baja señal en mapa ADC (c). En las imágenes de RMmp de control 8 meses después de la RMmp inicial ( $d$, e y f) existe resolución del cuadro. PSA = 1,17 ng/ml, como también de los hallazgos imagenológicos en secuencias morfológica T2 y funcional de DWI/ADC. 


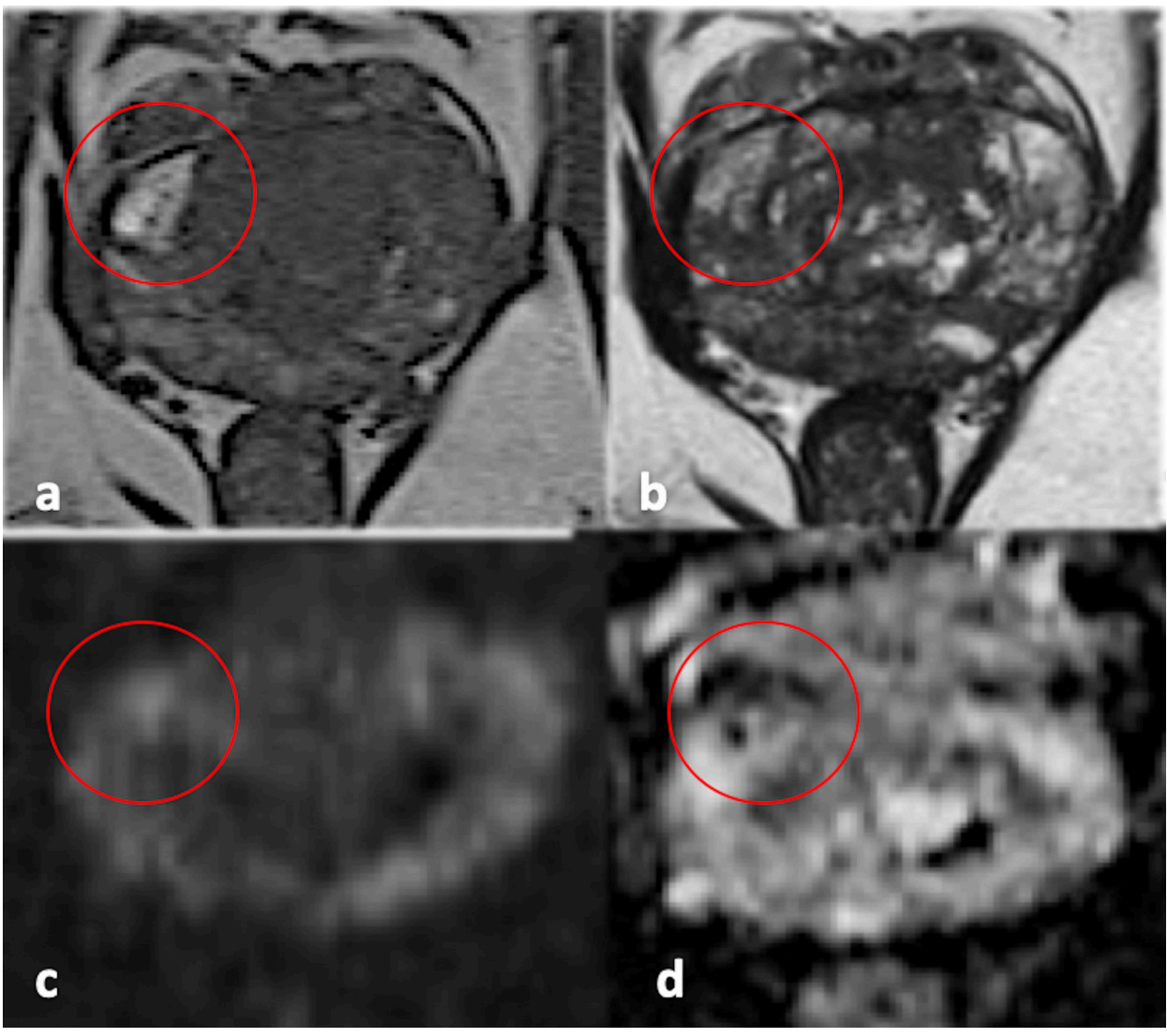

Figura 14: Un foco hemorrágico puede restringir en DWI (cyd) y pudiese ser de baja señal en T2 (b) y no debe ser interpretado como neoplasia. La clave es observar la secuencia T1 donde los restos hemáticos son de alta señal en T1 (a) (marcador).

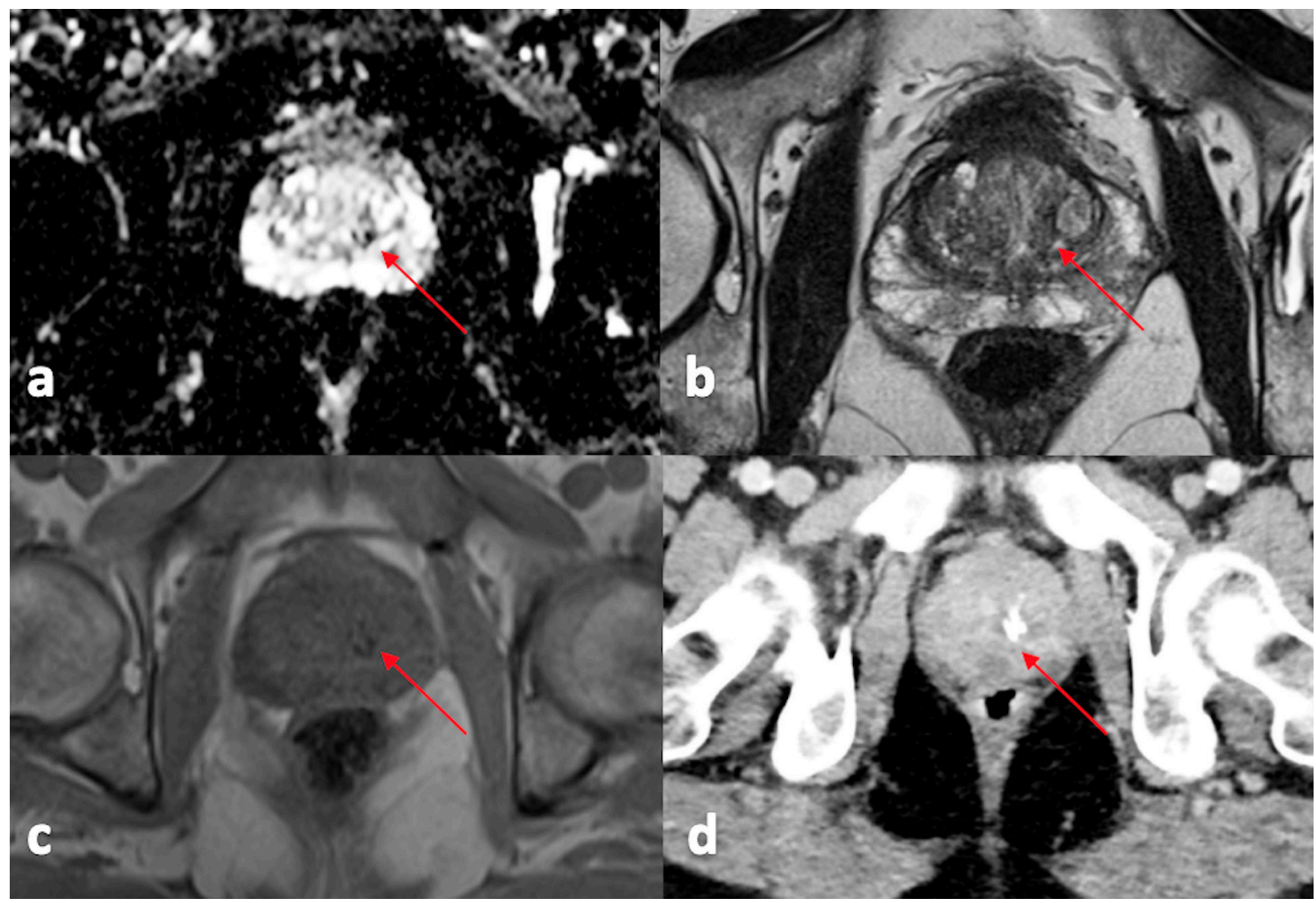

Figura 15: Calcificaciones. Otros pitfalls. Calcificaciones en la zona de transición. Se identifican calcificaciones en la zona de transición las cuales presentan baja señal en mapa $A D C$ (a) y baja señal T2 (b), lo que no debe ser interpretado como una lesión. Se identifica de baja señal T1 (c). En (d) podemos corroborar en TC del mismo paciente que se corresponden a calcificaciones. 


\section{Referencias}

1. Turkbey B, Rosenkrantz AB, Haider MA, et al. Prostate Imaging Reporting and Data System Version 2.1: 2019 Update of Prostate Imaging Reporting and Data System Version 2. European Urology.

2. Rosenkrantz AB, Taneja SS. Radiologist, Be Aware: Ten Pitfalls That Confound the Interpretation of Multiparametric Prostate MRI. American Journal of Roentgenology. 2013; 202(1): 109-120.

3. Panebianco V, Barchetti F, Barentsz J, et al. Pitfalls in Interpreting mp-MRI of the Prostate: A Pictorial Review with Pathologic Correlation. Insights into Imaging. 2015; 6(6): 611-630.
4. Panebianco V, Giganti F, Kitzing YX, et al. An update of pitfalls in prostate mpMRI: a practical approach through the lens of PI-RADS v. 2 guidelines. Insights into Imaging. 2018; 9(1): 87-101.

5. Kitzing YX, Prando A, Varol C, Karczmar GS, Maclean F, Oto A. Benign Conditions That Mimic Prostate Carcinoma: MR Imaging Features with Histopathologic Correlation. Radiographics. 2016; 36(1): 162-175.

6. Liu X, Verma S. Common Technical and Anatomical Pitfalls in the Evaluation of Multiparametric Prostate Magnetic Resonance Imaging. Seminars in Roentgenology. 2015; 50(4): 294-304. 